\title{
COMPARISON OF PAIN PERCEIVED BY PATIENTS UNDERGOING INTRA ORAL LOCAL ANESTHESIA USING DIFFERENT NEEDLE GAUGES
}

\author{
Noor Ul Sabah Hussain, Shoaib Younus, Uzair Bin Akhtar*, Malik Ali Hassan Sajid**, Muhammad Salman Chishty, \\ Saud Iqbal ${ }^{* * *}$ \\ Central Military Hospital, Lahore Medical College, Lahore Pakistan, *Sharif Medical and Dental College, Lahore Pakistan, **FMH College of \\ Medicine and Dentistry, Lahore Pakistan, ${ }^{* * * K E M U / M a y o ~ H o s p i t a l, ~ L a h o r e ~ P a k i s t a n ~}$
}

\begin{abstract}
Objective: To compare the difference in pain perceived by patients undergoing intra-oral local anesthesia with different gauge needles.

Study Design: Qausi experimental study.

Place and Duration of Study: Oral and Maxillofacial surgery department of Institute of Dentistry, Combined Military Hospital, Lahore Medical College, Lahore, from July 2019 to August 2019.

Methodology: One hundred patients were selected by consecutive sampling from the oral surgery OPD clinic. They were divided into two groups A and B randomly. Twenty three gauge needle on a 3cc disposable syringe was used for inferior alveolar nerve block and buccal nerve block for group A and 27 gauge needle on a metal dental syringe was used for the same in group B. Patients gave a verbal pain score, from 0-10 for each injection.

Results: One Hundred participants were included in study, 37 (37\%) males and 63 (63\%) females. Mean pain score for group A for the inferior alveolar nerve block was $4.50 \pm 2.1$ and group B was $3.86 \pm 2$. The mean pain score for the buccal nerve block in group A was $4.02 \pm 1.7$, while that of group B was $3.94 \pm 1.8$. There was no significant difference $(p=0.167 \& 0.855)$ in pain perceived by patients undergoing intra oral local anesthesia using needles of different gauges.

Conclusion: There is no difference in pain perceived by patients undergoing intra oral local anesthesia using needles of different gauges.
\end{abstract}

Keywords: Local anesthesia, Oral surgery, Pain perception.

This is an Open Access article distributed under the terms of the Creative Commons Attribution License (http://creativecommons.org/licenses/by/4.0), which permits unrestricted use, distribution, and reproduction in any medium, provided the original work is properly cited.

\section{INTRODUCTION}

Fear of pain from dental injections is a contributing factor resulting in avoidance of dental treatment by some patients ${ }^{1}$. Pain has different elements, one of which results from physical injury when the needle pierces the tissues ${ }^{2}$. Be it pediatric patients or adults, the idea of injection or a 'shot' coupled with dental treatment is a fear inducing thought for many individuals. While all of these may not be controlled, some aspects may be controlled to make the patients more comfortable. Thus, the search for the most painless method to administer anesthesia will continue and may vary depending on operator preference and experience and patients' past experiences.

The idea of administering painless dental

Correspondence: Dr Noor Ul Sabah Hussain, 365-B Canal View Housing Society, Lahore Pakistan

Received: 10 May 2020; revised received: 15 Sep 2020; accepted: 16 Sep 2000 injections continues to challenge the modern-day clinician and provides room for improvement. Several methods have been proposed and discussed for making dental injections less unpleasant and painful, these include; use of smaller gauge needles, use of topical anesthetic gel, pre-cooling of injection site 3 , warming of anesthetic solution, use of vibration and pressure at site of injection, slower speed of injecting by using computercontrolled anesthesia delivery systems and finally nanobot technology ${ }^{2,4}$. Different methods of reducing anxiety along with these techniques are often employed to help patients have a better dental treatment experience ${ }^{5}$.

Needle gauge has been under debate since a long time, and continues to be a cause of conflicting opinions and preferences among clinicians. While some authors suggest that using a larger needle gauge has significantly lower pain scales ${ }^{6,7}$ 
in different areas of the oral cavity, there is equally strong evidence that suggests that needle gauge has no impact on pain perception ${ }^{8}$.

The current study took into consideration the needle gauge and compared the pain perception of patients undergoing local anesthesia with a 23 gauge needle on a $3 \mathrm{cc}$ disposable syringe to a conventional 27 gauge needle on a metallic dental syringe. The aim of the study was to assess if there was any difference in pain perceived by these two needle gauges for inferior alveolar nerve block and buccal nerve block separately. The null hypothesis was that there would be no difference in pain based on needle gauge used for administration of intra-oral local anesthesia. To the best of the author's knowledge there is limited national data available on this topic and no such study (which compares a 23 gauge needle) has been conducted in the published English literature searched by the author.

The rationale for selecting 23 gauge needle on a $3 \mathrm{cc}$ disposable syringe was that these syringes are easily available in the market, easily procurable at a low cost and eliminate the need of cleaning, packing and sterilization of metal dental syringes.

\section{METHODOLOGY}

This quasi experimental study was carried out in Institute of Dentistry, Central Military Hospital, Lahore Medical College, from July 2019 to August 2019. It was approved on 23rd May 2019, by the Ethics Review Board (Case no.\#396/ ERC/CMH/ LMC). The study was carried out in the department of Oral and Maxillofacial Surgery of the Institute of Dentistry, CMH LMC. A sample size of 100 was calculated (50 for each group) using Statulator: An online statistical calculator ${ }^{9}$. Mean from a similar study done by Alexander et $a l^{6}$ was used with expected mean values of 2.37 and 2.80 .

Patients were selected using consecutive sampling. Two groups were made. Each group had 50 participants which were randomly allocated using computer generated random tables. Group A (case) underwent local anesthetic injec- tion with a 23 gauge needle on a 3cc disposable syringe, group B (control) underwent local anesthetic injection with a 27 gauge needle on a conventional metal dental syringe, using $2 \%$ lignocaine with 1:100,000 epinephrine in both groups.

A verbal consent was taken from each patient and the patients were told to rate their pain using a Numeric Pain Rating Scale (NPRS), a scale of $0-10,0$ being no pain and 10 being severe pain for two injections: inferior alveolar nerve block and buccal nerve block. Topical anesthesia was not used in both groups. The inferior alveolar nerve block was given first and the patient was asked to give a score for their pain. This was followed by the buccal nerve block and the patient then gave a pain score for this. This allowed for immediate response of the patient to be recoded. Basic demographic data recorded included age and gender of patients. Inclusion criteria was willingness to participate in this study, no current use of analgesics. Only patients advised dental extractions in the lower jaw, requiring both the inferior alveolar nerve block and the buccal nerve block were included in the study. Patients with severe infection or limited mouth opening were excluded from the study. Patients who were anxious or already taking analgesics for dental pain or did not give consent to be a part of the study were also excluded.

Data was recorded and analyzed using SPSS. A $p$-value of less than 0.05 was considered significant. Data was not distributed normally so Mann Whitney $U$ test was carried out to compare the difference in mean, median and interquartile of pain scores given by patients in each group.

\section{RESULTS}

A total of 100 participants were included in this study. There were $37(37 \%)$ males and $63(63 \%)$ females. Mean age of participants was $39.87 \pm 13.1$, median age was $35,95 \%$ CI for mean: lowerbound 36.37, upper bound 41.57 . Mean age of males was $40.35 \pm 14.4$ and females was $38.2 \pm 12.3$.

The mean pain score for the inferior alveolar nerve block for group A was $4.50 \pm 2$.1, Interquar- 
tile range 3 , and group B was $3.86 \pm 2$ with interquartile range 3 . The difference in the two groups was statistically non-significant with $p$-value 0.167. Detailed comparison shown in table-I.

The mean pain score for the buccal nerve block in group A was $4.02 \pm 1.7$ with Interquartile range of 2 , while that of group B was $3.94 \pm$

Table-I: Comparison between inferior alveolar nerve block pain scores show no significant difference between the two groups.

\begin{tabular}{l|c|c|c}
\hline Group & Mean & Median & IQR \\
\hline $\mathrm{A}$ & $4.50 \pm 2.11$ & 5 & 3 \\
\hline $\mathrm{B}$ & $3.86 \pm 1.96$ & 4 & 3 \\
\hline \multicolumn{2}{ll}{ p-value $=0.167$}
\end{tabular}

Table-II: Comparison between buccal nerve block pain scores show no significant difference between the two groups.

\begin{tabular}{l|c|c|c}
\hline Group & Mean & Median & IQR \\
\hline $\mathrm{A}$ & $4.02 \pm 1.67$ & 4 & 2 \\
\hline $\mathrm{B}$ & $3.94 \pm 1.79$ & 4 & 2 \\
\hline \multicolumn{2}{ll}{$p$-value $=0.855$}
\end{tabular}

Table-III: Gender distribution amongst the groups.

\begin{tabular}{l|c|c}
\hline Groups & Male & Female \\
\hline A (Conventional) & $15(40.5 \%)$ & $35(55.6 \%)$ \\
\hline B (Disposable) & $22(59.5 \%)$ & $28(44.4 \%)$ \\
\hline
\end{tabular}

Table-IV: Comparison of pain scores for inferior alveolar nerve block between males and females show insignificant difference.

\begin{tabular}{l|c|c}
\hline Group & Median & IQR \\
\hline Males & 3 & 3 \\
\hline Females & 5 & 3 \\
\hline$p$-value $=0.2$
\end{tabular}

Table-V: Comparison of pain scores for inferior buccal nerve block between males and females show insignificant difference.

\begin{tabular}{l|c|c}
\hline Group & Median & IQR \\
\hline Males & 4 & 3 \\
\hline Females & 4 & 2 \\
\hline p-value $=0.4$
\end{tabular}

1.8 with interquartile range of 3 . The difference in the two groups was statistically non-significant with $p$-value 0.855. Detailed comparison with median values shown in table-II.

Gender distribution showed 37\% males and $63 \%$ females, with a median pain score of 3.0 and 5.0 for males and females respectively for inferior alveolar nerve block. For buccal nerve block the mean scores for males and females were 4.0 and
4.0 respectively. The differences in these scores were statistically insignificant ( $p=0.2$ and 0.4$)$, table-III, IV and V show these results.

\section{DISCUSSION}

Needle gauge refers to the diameter or size of the lumen of a needle. The bigger the number the smaller the size. For example, a 27 gauge needle has a smaller lumen diameter than a 23 gauge needle. Needles for dental anesthesia come in different gauges. Most commonly used gauges are $25,27,30^{10}$.

In the current study, there was no significant difference in pain felt by patients during administration of local anesthesia by different gauge needles. These results are in line with studies carried out by Fuller ${ }^{8}$ and Lehtinen ${ }^{11}$. Albiet old, both studies were carried out on adults and showed that needle gauge did not significantly impact the pain perception by patients. According to Melamed, there is no significant difference in pain when different needle gauges are used for administration of local anesthesia intraorally ${ }^{10}$. Mcpherson et al, in 2015, studied the difference between $27 \mathrm{G}$ large bore sized and 27 $G$ standard bore sized dental needle for pain perception and concluded that there was no significant difference between the two ${ }^{12}$.

Scarce data is available in English literature comparing needle gauge and pain perception intra-orally for adults. Recent literature shows a comparison of 30 gauge needles (ultrashort disposable insulin syringes) with conventional needles (27 G, 26 G) in pediatric patients. In 2017 Kaur et al ${ }^{7}$ reported a significantly lower pain score with use of a $30 \mathrm{G}$ disposable syringe. Same was observed by Alexander et al ${ }^{6}$. Ghasemi ${ }^{13}$ reported a significant difference in pain perceived by patients undergoing intraoral local anesthesia using $30 \mathrm{G}$ needles when compared to $27 \mathrm{G}$. The studies by Kaur et $a l^{7}$, Alexander et al and Ghasemi ${ }^{13}$ were however carried out on pediatric patients. A study by Puri ${ }^{14}$ in 2018 also gave better pain scores with a $30 \mathrm{G}$ superfine needle when used to administer the greater palatine and nasopalatine block but attributed this to syringe 
design rather than gauge difference. The insulin syringe offering a more graded and controlled rate of administration and is colorful and less frightening to the patients as stated by Puri14. In a similar study, by Janani and Kumar in 2018, 30 G had significantly lower pain scores ${ }^{15}$.

In the current study there was no significant difference in pain perceived by male and female patients. This was the same in the study by Kaur et $a l^{7}$ and Janani and Kumar ${ }^{15}$ where no significant differences were found between pain scores for men and women receiving dental anesthesia. However another study shows that gender has an important role to play in pain perception with women more likely to experience more pain with the same stimulus than men ${ }^{16}$.

The 3cc disposable syringe is easily available in the market and is available in a sterile pack as an assembled system whereas, metal dental syringes have many parts that need to be cleaned, washed and then packed by an operator/assistant. The disposable syringe is lighter in weight and easier to handle than the metal syringe as it smaller in length. A study conducted by Wiener et al on dental students and hygienists concluded that $62.2 \%$ of the subjects preferred a petite syringe. Females and individuals with smaller hands may prefer smaller syringe due to better control and ease of aspiration ${ }^{17}$. A $23 \mathrm{G}$ needle has a bigger lumen than the conventional $27 \mathrm{G}$ needle and this allows for better aspiration which is mandatory for safe delivery of intra-oral local anesthesia as shown by a study comparing the 27 $\mathrm{G}$ and $30 \mathrm{G}$ needle for positive aspiration ${ }^{18}$. Another advantage of using a bigger gauge needle (23 G) would be better strength of the needle and even lesser chances of breakage of needle which may cause complications ${ }^{19}$ which although rare may become serious and require surgical removal under general anesthesia ${ }^{20}$.

Unfortunately, drug availability in dental cartridge form is not always reliable in our market, as supplies often run short. Moreover, the only combination available is lidocaine with epinephrine by different brands. Often in dentistry, the need arises for lidocaine without epinephrine or 'plain' local anesthesia in patients with hypertension and other systemic diseases present. It is integral to control the dose of epinephrine in these patients ${ }^{5}$. The $3 \mathrm{cc}$ disposable syringes can be filled with different drugs to address these needs. Plain local anesthesia is readily available in the market in $10 \mathrm{ml}$ vials. Market survey also reveals that using $3 \mathrm{cc}$ syringes is a cheaper alternative in terms of syringe as well as drug used. One dental cartridge of $1.8 \mathrm{ml}$ costs around Rs.50 on average, whereas a $10 \mathrm{ml}$ ampule of the same composition of the drugs costs less than Rs.20. The cost of 3cc disposable hypodermic syringe is around Rs.15 and the cost of dental needle reaches upto Rs.10, let alone the cost of cleaning, washing, drying, packing and autoclaving of the conventional metallic dental syringe.

With disposable syringes there is also the advantage of less generation of sharps; eliminating the double ended conventional dental anesthesia needles and contaminated glass cartridges. Decreasing the exposure of the clinician and the staff of the operatory/dental institute to the sharps; in terms of dental needles and contaminated glass cartridges.

While needle gauge continues to remain under debate newer needles and syringe variations are being introduced and tested. While the telescopic needles seem promising ${ }^{21}$, different bore sized needles claiming to be less painful clinically do not produce the said results ${ }^{12}$, further research to produce ergonomic syringes is encouraged ${ }^{17}$. It is also thought provoking that the disposable or smaller/petite syringe may be preferred by patients as it is perceived to cause less pain and fear ${ }^{14}$.

\section{CONCLUSION}

In light of the current study the author recommends the use of $23 \mathrm{G}$ needles on disposable syringes as there is no difference in pain perception by patients and these syringes are easily procurable, cheaper, do not need cleaning and washing and decreased contaminated waste 


\section{when compared with conventional metal syrin- ges used in dentistry. \\ CONFLICT OF INTEREST}

This study has no conflict of interest to be declared by any author.

\section{REFERENCES}

1. Siddiqui T, Wali A, Abdullah H, Khan FN, Tanvir R, Siddiqui M. Evaluation of fear of injections and its association with avoidance of dental treatment. J Restor Dent 2016; 4(3): 81-88.

2. Angelo Z, Polyvios C. Alternative practices of achieving anaesthesia for dental procedures: a review. J Dent Anesth Pain Med 2018; 18(2): 79-85.

3. Bilsin E, Güngörmüş $Z$, Güngörmüş $M$. The efficacy of external cooling and vibration on decreasing the pain of local anesthesia injections during dental treatment in children: a randomized controlled study. J Perianesthesia Nurs 2020; 35(1): 44-47.

4. Sriram K, Selvarasu K. Adjunct techniques for painless intraoral local anesthesia - A systematic review. Drug Invent Today 2018; 10(1): 2761-68.

5. Hupp JR, Ellis III E, Tucker MR. Contemporary oral and maxillofacial surgery. $6^{\text {th }}$ ed. Falk K, Sprehe C, editors. Elsevier Inc; 2014.

6. Asokan A, Rao A, Mohan G, Reddy NV, Kumar K. A pain perception comparison of intraoral dental anesthesia with 26 and 30 gauge needles in 6-12-year-old children. J Pediatr Dent 2014; 2(2): 56.

7. Singh C, Kour G, Masih U, Srivastava M, Yadav P, Kushwah J. Insulin syringe: a gimmick in pediatric dentistry. Int $\mathrm{J}$ Clin Pediatr Dent 2017; 10(4): 319-23.

8. Fuller NP, Menke RA, Meyers WJ. Perception of pain to three different intraoral penetrations of needles. J Am Dent Assoc 1979; 99(5): 822-24.

9. Dhand NK, Khatkar M. Statulator [Internet]. 2014. Available from: http://statulator.com/SampleSize/ss2M.html

10. Melamed SF. Handbook of Local Anesthesia. Elsevier Inc. Br J
Anaesthesia 2013; 6(110): 666-67.

11. Lehtinen R. Penetration of 27 - and 30 -gauge dental needles. Int J Oral Surg 1983; 12(6): 444-45.

12. McPherson JS, Dixon SA, Townsend R, Vandewalle KS. Effect of needle design on pain from dental local anesthetic injections. Anesth Prog 2015; 62(1): 2-7.

13. Ghasemi D, Rajaei S, Aghasizadeh E. Comparison of inferior dental nerve block injections in child patients using 30-gauge and 27-gauge short needles. Dent Mater J 2014; 3(2): 71-76.

14. Puri SS. Comparison of the pain intensity associated with injection using standard needle and super-fine super $30 \mathrm{~g}$ short needle. Int J Curr Res 2018; 10(11): 75592-93.

15. Janani K, Kumar MPS. Comparison of pain perception with conventional syringe and insulin syringe during greater palatine nerve block. Drug Invent Today 2018; 10(7): 1185-89.

16. Bhadauria US, Dasar PL, Sandesh N, Mishra P, Godha S. Effect of injection site pre-cooling on pain perception in patients attending a dental camp at life line express: A split mouth interventional study. Clujul Med 2017; 90(2): 220-25.

17. Wiener RC, Crout RJ, Sandell J, Howard B, Ouassa L, Wearden $\mathrm{S}$, et al. Local anesthetic syringe ergonomics and student preferences. J Dent Educ 2009; 73(4): 518-22.

18. Labuschagne W. Evaluation of two different-gauge dental needles for the presence of blood following the application of local anesthesia by dental students. South African Dent J 2015; 70(1): 17-21.

19. Acham S, Truschnegg A, Rugani P, Kirnbauer B, Reinbacher KE, Zemann W. Needle fracture as a complication of dental local anesthesia: recommendations for prevention and a comprehensive treatment algorithm based on literature from the past four decades. Clin Oral Investig 2019; 23(3): 1109-19.

20. Brooks J, Murphy MT. A novel case of a broken dental anesthetic needle transecting the right internal carotid artery. J Am Dent Assoc 2016; 147(9): 739-42.

21. Aghahi RH, Nassab SARG, Eskandarizadeh A, Saidi AR, Shahravan A, Hashemipour MA. Telescopic dental needles versus conventional dental needles: comparison of pain and anxiety in adult dental patients of kerman university of medical sciences. A randomized clinical trial. J Endod 2017; 43(8): 1273-78. 